\title{
PLASMA POLYMERIZATION OF ORGANOSILICON COMPOUNDS BY THE SELF-BIAS METHOD
}

\author{
TAKAO HIRAIDE, HIDEO YAMADA \\ Department of Chemistry, Tochigi-Ken Kennan Kogyo Shidosho, \\ Tochigi, 327 JAPAN \\ OSAMU TSUJI \\ SAMCO International Inc., \\ Takeda Fushimi-ku, Kyoto 612 JAPAN
}

Organosilicon compounds were deposited in an RF cathode coupled plasma using Tetramethoxy silane. The films were deposited on silicon and glass substrates in negative self-bias voltages over the range of $-80 \mathrm{~V}$ to $-580 \mathrm{~V}$. The deposited films were highly crosslinked and optically highly transparent between optical wavelengths from $420 \mathrm{~nm}$ to $1000 \mathrm{~nm}$ when oxygen was infused with the monomer.

\section{Introduction}

Plasma deposited silicon oxide films have been used for protective hard coating and optically transparent film for plastics and optical windows.[1] We have reported an RF plasma self-bias reactor system for deposition of silicon oxide films using an organosilicon compound as a Vinyltrimethoxy silane monomer. In the previous paper[2], we have reported self-bias method gives much higher deposition rate other than anode-coupled plasma reactor.

In this paper we present the results of deposited films under various plasma conditions as a function of negative self-bias voltage using Tetramethoxy silane (TMOS). We discuss the film characteristics and investigate the growth mechanism of the films in the self-bias cathode coupled plasma. 


\section{Experimental}

The plasma polymerization equipment used in the present experiment is the PD-10S manufactured by SAMCO International, Kyoto Japan. Figure 1 shows a schematic of its reactor which has been modified into a cathode coupled plasma reactor. The experimental procedure involved pumping the reactor evacuate to a pressure below $5 \times 10^{-5}$ torr using a mechanical rotary pump and oil diffusion pump, after which TMOS monomer was introduced with reactor pressure regulated by a fine needle valve. RF power between 10 - 150 watts was then applied for the deposition times of 5 - 15 minutes, and films were deposited on the silicon or cover glass substrate.

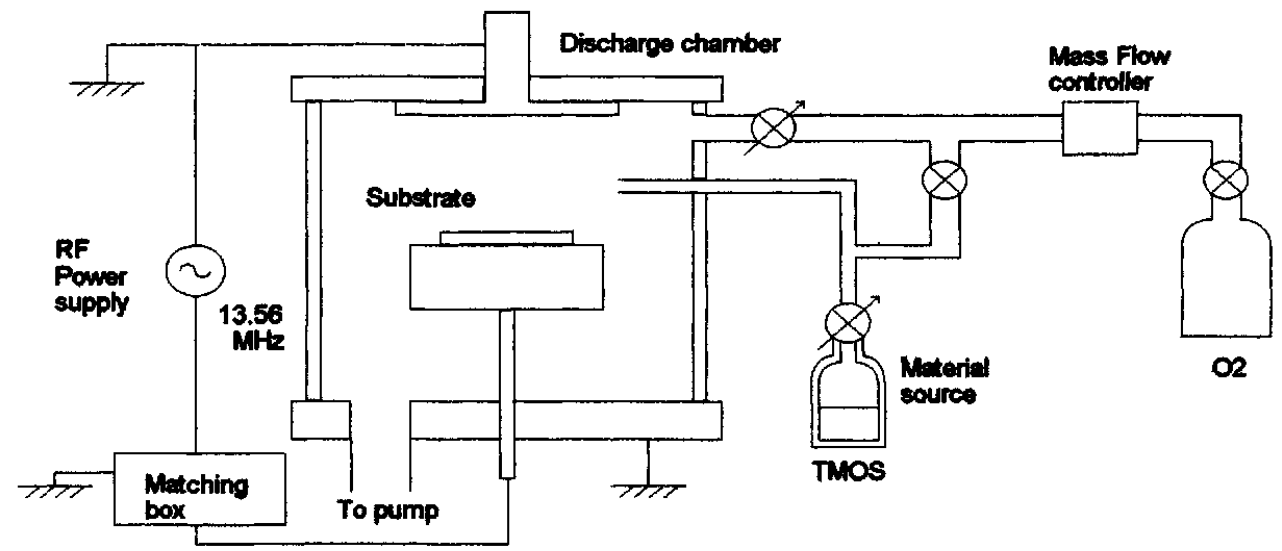

Figure 1. An RF Self-bias Plasma Reactor

\section{Results and Discussion}

\section{Deposition Rate and Density}

The level of self-bias voltage $(\mathrm{Vb})$ is directly related to such factors as applied power, reactor pressure, distance between electrodes, and the ratio upper and lower electrode areas. As we shown in Fig. 2, self-bias is proportional to applied voltage, and is affected by reactor pressure.

Figure 3 shows the relationship between self-bias voltage, deposition rate, and film density. This data indicates clearly that as

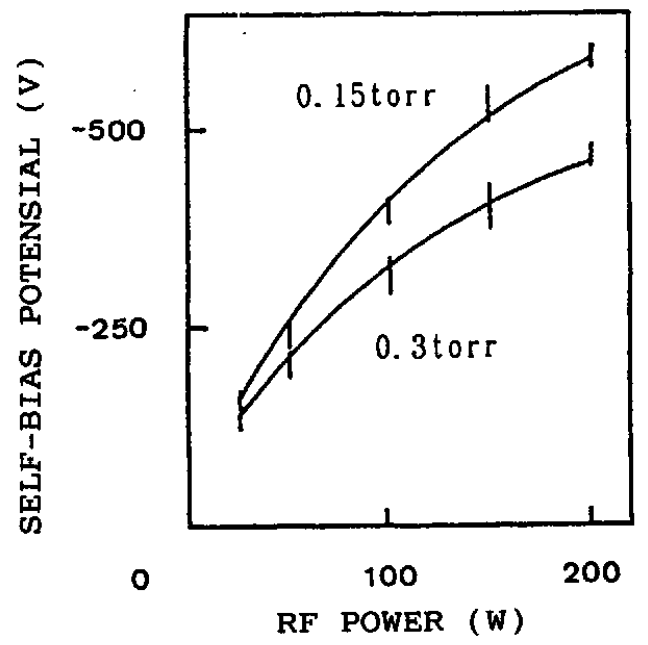

Figure 2. Dependence of Self-Bias Potential on RF Power 
$\mathrm{Vb}$ grows, the deposition rate increases at both levels of reactor pressure until eventually leveling off. We observe surface temperature of the substrate electrode by thermo-tape during polymerization, it was noticed that there was an increase in temperature proportional to time and selfbias Voltage.

Wood et al [3] examined the relationship between substrate temperature and deposition rate during the deposition of amorphous carbon film, and concluded that the deposition rate was faster at low temperatures than at high substrate temperatures because at low substrate temperatures the adsorption of fragments increases and the sputtering effects are reduced.

In the case of polymerization of TMOS it also shows that an increase of $\mathrm{Vb}$ causes a increase of substrate temperature. As the result, the deposition rate seems to be increased by the above factors. It is also suggest that films deposited under high $\mathrm{Vb}$ show highlly crosslinking due to increased ion bombardment.

\section{Composition of Films}

Figure 4 shows the result of EDS spectrum of a typical film. This equipment is configured for boron (B) and is not able to qualify hydrogen, but $\mathrm{C}, \mathrm{O}$ and $\mathrm{Si}$ were detected from the film.

Figure 5 shows the infrared spectrum of each films. Each reversion is assigned as follows:

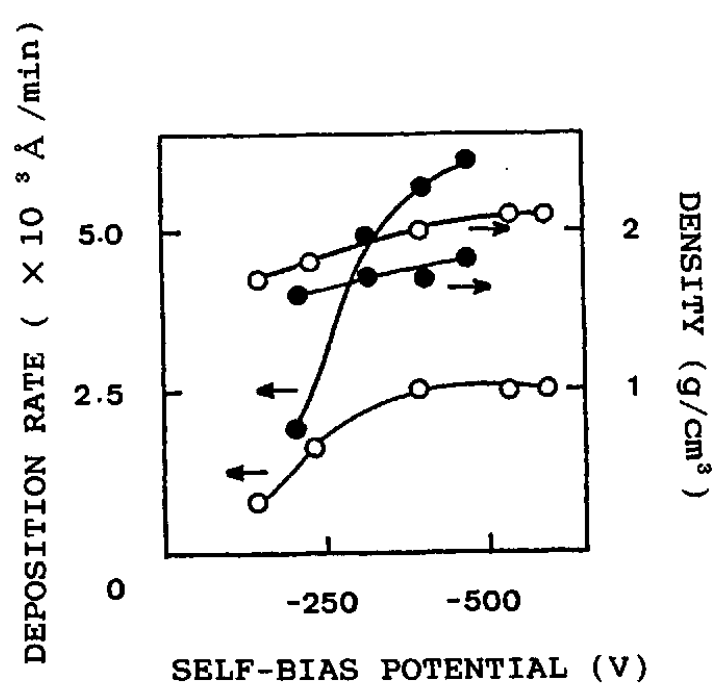

Figure 3. Deposition Rate and Film Density at Different Self-Bias Potential

$$
-\bigcirc: 0.15 \text { torr, }-0: 0.3 \text { torr }
$$

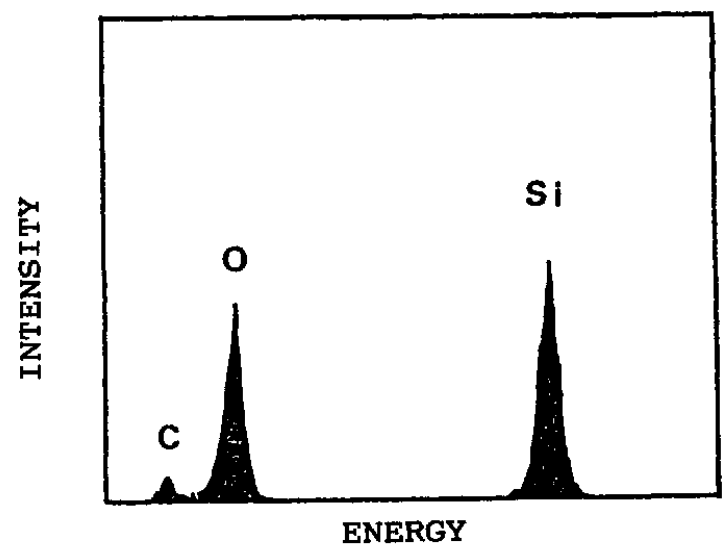

Figure 4. EDS Spectram of the Deposited Films 


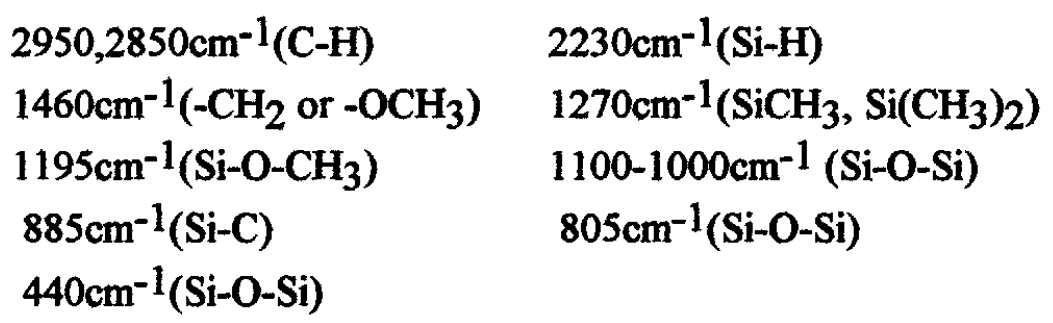

Films obtained in low $\mathrm{Vb}$ are polymers that leave intact part of the source monomer composition. Since the adsorption peak shows bonding between silicon, hydrogen and carbon atoms, it is suggested that $\mathrm{Si}-\mathrm{C}$, $\mathrm{O}-\mathrm{C}$, and $\mathrm{C}-\mathrm{H}$ rebonded after initial disassociation.

On the other hand, absorption peak of films obtained at high $\mathrm{Vb}$ is almost all absorption peaks based on Si-O$\mathrm{Si}\left(1032,805,440 \mathrm{~cm}^{-1}\right), \quad$ and some absorption peak of $\mathrm{Si}-\mathrm{C}\left(885 \mathrm{~cm}^{-1}\right)$ and $\mathrm{OH}$ (around $3600 \mathrm{~cm}^{-1}$ ) are observed. From this results it can be seen that the film configuration shows highly crosslinked SiO-Si crosslinked bonding, but it suggested that the films are not completely oxidized as a silicon dioxide.

\section{Wettability of Films}

Figure 6 shows the wettability of films deposited at different $\mathrm{Vb}$ levels were measured contact angle after deposition (Thickness: about $1 \mu \mathrm{m}$ ). Wettability of the surface is variable and dependent on $\mathrm{Vb}$. We observed the higher $\mathrm{Vb}$ is, the more hydrophilic surfaces. This results suggested influenced by the amounts of hydrophobic functional groups (methyl radical etc.) and

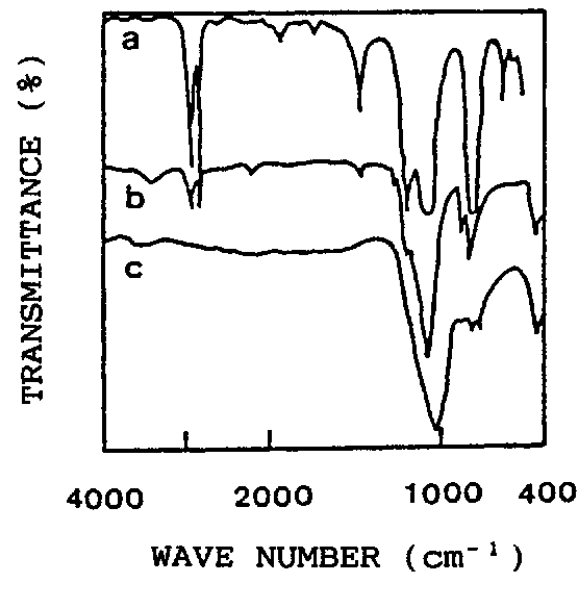

Figure 5. IR Spectra of the Films Deposited at Diffrent Self-Bias Potential

a: $\mathrm{Si}\left(\mathrm{OCH}_{3}\right)_{4}, \mathrm{~b}:-80 \mathrm{~V} \mathrm{C}:-580 \mathrm{~V}$

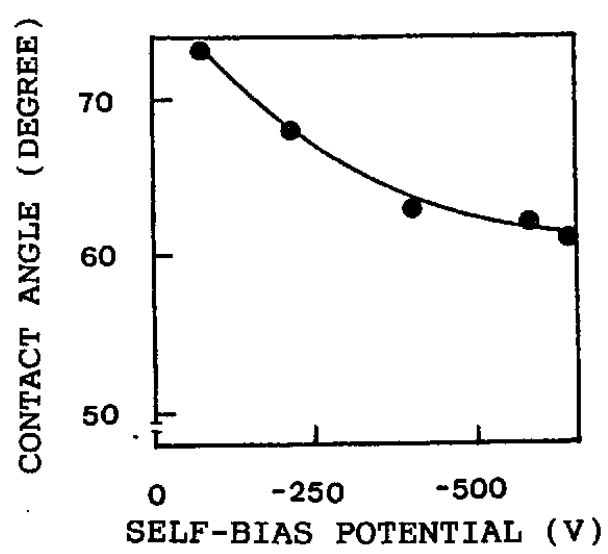

Figure 6. Self-Bias Voltage and wettability 
corresponds with the result of infrared absorption spectrum.

\section{Reaction in Plasma and Ion Sheath}

It is known that different film structure are produced by reactions in balk plasma and reactions in the ion sheath. This is because the substrate electrode is negatively charged and is affected by the bombardment of positive ion impacts. In order to further examine this, we examine moved the position of substrate and compared the reaction in the plasma.

Figure 7 shows a comparison of the deposition rate. As the substrate is moved further away from the cathode, the deposition rate and films hardness are decrease. The boundary was the area dividing the plasma and the ion sheath.

Regarding the reaction mechanism of plasma polymerization, whether the polymerization activated species are ions or neutral radicals depends on reactor structure. Our experimental data shows clearly that the influence of ion impact on deposition rate, hardness and film density.

Figure 8 shows infrared absorption spectrum of films grown in the sheath and the bulk plasma.

Films grown in bulk plasma show absorption of

$$
\begin{aligned}
& -\mathrm{CH}_{3}\left(2950 \mathrm{~cm}^{-1}\right),-\mathrm{CH}\left(2847 \mathrm{~cm}^{-1}\right), \\
& \mathrm{SiH}\left(2235 \mathrm{~cm}^{-1}\right),-\mathrm{SiCH}_{3}, \\
& -\mathrm{Si}\left(\mathrm{CH}_{3}\right)_{3}\left(1268 \mathrm{~cm}^{-1}\right),-\mathrm{SiC}\left(885 \mathrm{~cm}^{-1}\right) \text { etc., }
\end{aligned}
$$
which is similar to the films obtaining at low $\mathrm{Vb}$. Therefore, reaction mechanism in the
$\underset{\leftarrow}{\stackrel{F}{E}}$

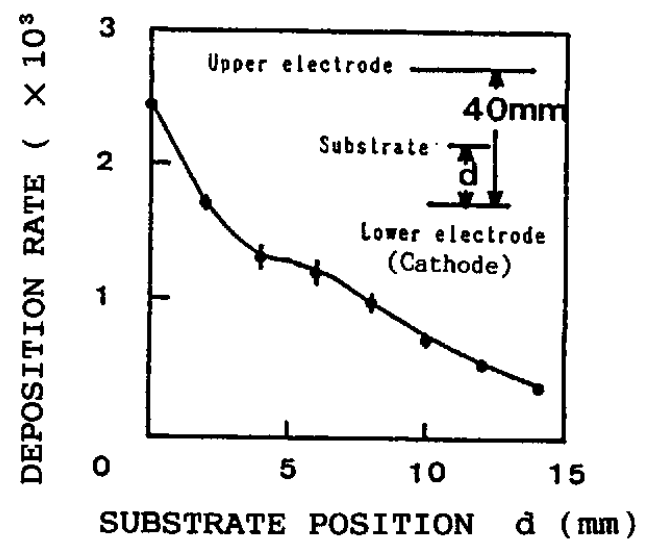

Figure 7. Deposition Rate and the Different Substrates Position

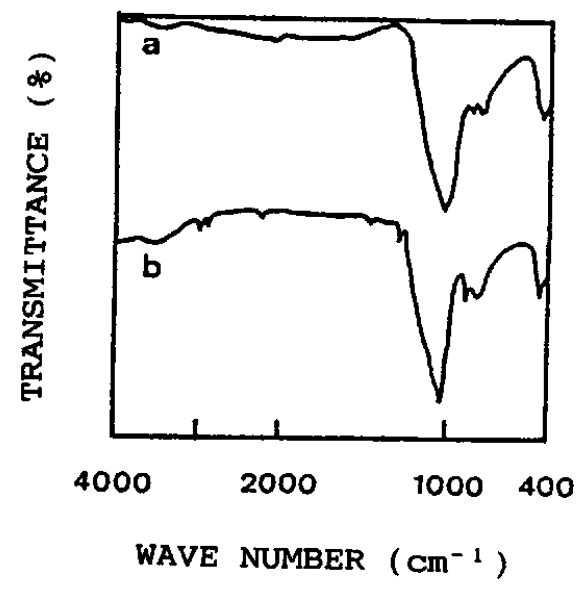

Figure 8. IR Spectra of the Deposited Films in a Sheath (a) and Bulk Plasma (b) 
ion sheath is assumed to be formed activated species by ion bombardment and simultaneously form crosslinking structures by dissociate molecular chains due to the polymerization process.

\section{Effect of Addition of Oxygen with the}

\section{Monomer}

The higher $\mathrm{Vb}$ condition, the resulting high hardness films. But at the same time the coloring of the film itself also becomes low transparency. To improve the low transparency of the films we examined the effect of adding oxygen. Figure 9 shows transmission of the spectrum for visible and near infrared.

When oxygen is added, transparency much improves visibly and allows for the growth of transparent films. Especially, the transparency of wavelengths below $570 \mathrm{~nm}$ was greatly improved.

The composition of the films was shown in figure 10 , we obtained at $\mathrm{Vb} ;-380 \mathrm{~V}, \mathrm{O}_{2}$; $200 \mathrm{ml} / \mathrm{min}$ shows infrared absorption spectrum a patterns similar to that of amorphous silicon dioxide. On the other hand, when films(b) obtained at $\mathrm{Vb} ;-110 \mathrm{~V}$, $\mathrm{O}_{2} ; 200 \mathrm{ml} / \mathrm{min}$ show clearly absorption based on $-\mathrm{OH}\left(3350,929 \mathrm{~cm}^{-1}\right)$.

If one of the possibility is that even when the ratio of monomer to oxygen is the same the difference of $\mathrm{Vb}$ (ion impact) influences film composition, it could be thought that ion impact affects and disassociation of dimer or polymer in the $\mathrm{SiO}_{2}$ formation process, and that

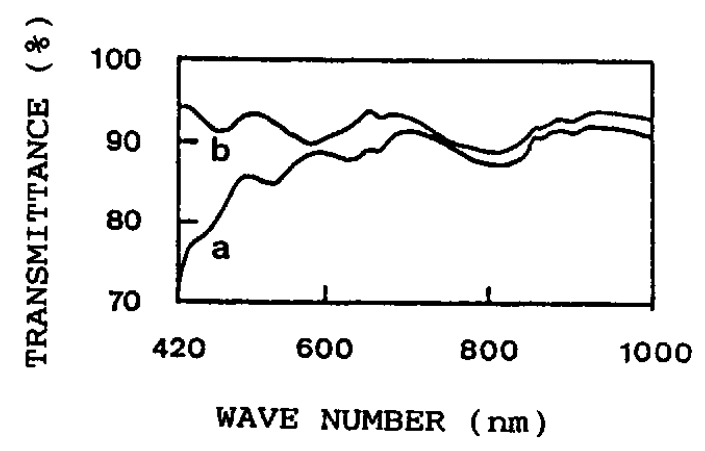

Figure 9. VIS/Near IR Spectra of the Deposited Films from TMOS and TMOS with $\mathrm{O}_{2}$

a: monomer only, b: monomer $/ \mathrm{O}_{2}$ gas

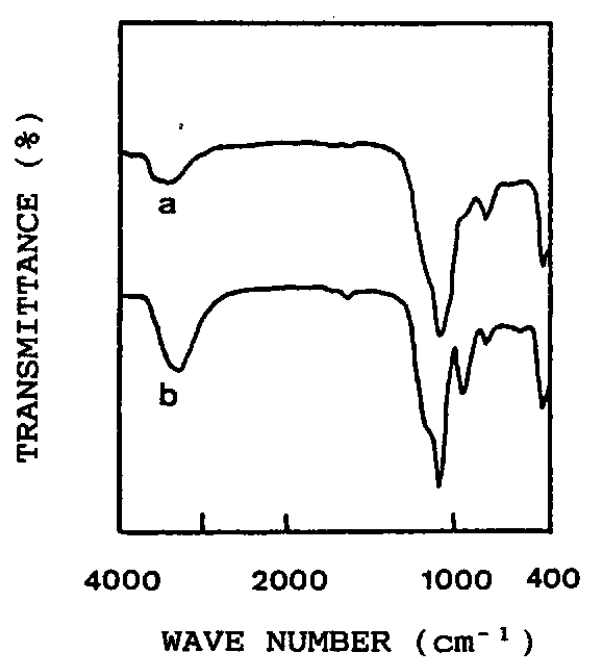

Figure 10. IR Spectra of the Deposited Films with Oxygen and TMOS

a: $-380 \mathrm{~V}, \mathrm{O}_{2} 200 \mathrm{ml} / \mathrm{min}$; b: $-110 \mathrm{~V}, 200 \mathrm{ml} / \mathrm{min}$ 


$$
-\mathrm{Si}-\mathrm{OH}+\mathrm{HO}-\mathrm{Si}-\rightarrow-\mathrm{Si}-\mathrm{O} \mathrm{Si}-
$$

the reaction must be greatly contributed to by ion bombardment.

Table 1 shows film density and knoop hardness obtained when oxygen is added. Adding oxygen increases film density to near the level of silicon dioxide. This is consistent with the results of infrared absorption spectrum as described above. Adding oxygen is also effective in improving knoop hardness, since with only monomer the hardness was $618 \mathrm{~kg} / \mathrm{mm}^{2}$ and when $100 \mathrm{ml} / \mathrm{min}$ of oxygen was added the hardness was $668 \mathrm{~kg} / \mathrm{mm}^{2}$ respectively.

Table 1. Film Density and Hardness of the Films with TMOS

\begin{tabular}{ccc}
\hline $\begin{array}{c}\mathrm{O}_{2} \text { flow rate } \\
(\mathrm{ml} / \mathrm{min})\end{array}$ & $\begin{array}{c}\text { density } \\
\left(\mathrm{g} / \mathrm{cm}^{3}\right)\end{array}$ & $\begin{array}{c}\text { knoop hardness } \\
\left(\mathrm{kg} / \mathrm{mm}^{2}\right)\end{array}$ \\
\hline 0 & 2.1 & 618 \\
20 & 2.2 & - \\
50 & 2.2 & - \\
100 & 2.3 & 668 \\
200 & 2.3 & - \\
\hline
\end{tabular}

\section{Conclusion}

Organosilicon compounds were deposited in a cathode coupled parallel plate electrode configured reactor using Tetramethoxy silane (TMOS) source materials. Under low self-bias conditions the resulting films displayed $\mathrm{Si}-\mathrm{C}, \mathrm{O}-\mathrm{C}$, and $\mathrm{C}-\mathrm{H}$ bonding. In high self-bias potential ranges the films were almost $\mathrm{Si}-\mathrm{O}-\mathrm{Si}$ silicon oxides. The addition of $\mathrm{O}_{2}$ during film deposition resulted in the improvement of film hardness and optical transparency. The increase in optical transparency was especially noteworthy for wavelengths below $590 \mathrm{~nm}$. 


\section{Acknowledgment}

The authors to express thanks Tetsuo Shibamiya in Tochigi Kennan Kogyo Shidosho for the helpful discussion during the experiment.

\section{References}

1. T. Wydeven, J.Appl. Optics, 16, 3(1977) 717

2. T. Hiraide, H. Yamada, H. Hoshino, O. Tsuji, T. Tatsuta, M. Sawai and P. Murawala, Proc. Jpn. Symp. on Plasma Chem., Tokyo, Japan, 3 (1990) 213.

3. P. Wood, T. Wydeven and O. Tsuji, Surface and Coatings Technology, 49 (1991) 399.

4. K. Ozaki, Kobunshi Ronbunshu, 46, 9 (1989) 565.

5. K.S. Chen, N. Inagaki, K. Katsuta, J. Appl. Polym. Sci., 27 (1982) 4655. 